\title{
Polar Lipids from Olives and Olive Oil: A Review on Their Identification, Significance and Potential Biotechnological Applications
}

\author{
Eliana Alves* (D), M. Rosário M. Domingues ${ }^{\mathbb{D}}$ and Pedro Domingues \\ Mass Spectrometry Centre, Department of Chemistry \& QOPNA, University of Aveiro, Campus Universitário \\ de Santiago, 3810-193 Aveiro, Portugal; mrd@ua.pt (M.R.M.D.); p.domingues@ua.pt (P.D.) \\ * Correspondence: elianaalves@ua.pt; Tel.: +351-234-370-695
}

Received: 15 June 2018; Accepted: 6 July 2018; Published: 10 July 2018

\begin{abstract}
Polar lipids are minor components of olives and olive oil and include a myriad of molecules such as phospholipids and glycolipids. Even though sensitive and high-resolution analytical approaches have been used to unveil the polar lipidome of these matrices, new insights on their composition are needed. In this review, we will describe the findings on the identification and characterization of polar lipids from olives and olive oil and the underlying analytical challenges. The significance of polar lipids will also be discussed as potential markers of identity and traceability of olives and olive oil and in detecting adulteration of olive oil. Their potential impact on nutrition and health will be presented as a valuable source of bioactive compounds and as promising ingredients for different uses from olive-derived industrial by-products.
\end{abstract}

Keywords: authentication; bioactive; by-product; glycolipid; lipidomics; mass spectrometry; phospholipid; traceability

\section{Introduction}

For millennia, olive oil has been an essential ingredient in the Mediterranean diet, as a food source of healthy fat. It is produced mostly by Spain, Italy, Greece and by other countries of Southern Europe and North Africa [1]. Nowadays, olive oil's economy has gained global importance, especially in gourmet cuisine, and its production has been extended to North and South Americas, Australia and Asia [1].

The increasing investment in the development of olive groves in these regions has been boosted by the benefits of olive oil's consumption which is directly related to its composition. Olive oil is mainly composed of triacylglycerols (Ca. 98\%) [2], primarily consisting of monounsaturated fatty acids, acknowledged for improving several cardiovascular risk factors [3]. In addition to the primary compounds, high-quality olive oils, such as virgin olive oils (VOOs), possess a plethora of minor components in the remaining $2 \%$ of their composition [2]. Some of the minor components confer distinct features to olive oil in terms of sensorial attributes and health benefits [4,5], and some components can be used for providing a chemical identity to olive oil [6].

Polar lipids are a group of minor components of olive oil [2]. The isolation, identification, and characterization of the minor components, such as polar lipids, might be essential to provide a molecular fingerprint for traceability and authenticity purposes [7]. The profiling of the major chemical components, such as triacylglycerols and total fatty acids, is insufficient to discriminate olives or olive oils, per se, and the simultaneous analysis of minor components is necessary [8]. VOOs are very susceptible to fraud and to tampering with other oils, as lower grade olive oils $[9,10]$. With recent analytical developments, new fast and sensitive methods have been claimed to evaluate olive 
oil's authenticity [11]. Therefore, it has become urgent to find foolproof analytical approaches and molecular markers to reveal a specific chemical identity for olives and olive oil and to detect adulterated olive oil [10]. Polar lipids have been suggested as promising molecular markers of identity [12,13]. Some research has been carried out towards their identification in olives and olive oil, mainly through mass spectrometry (MS)-based approaches, but there is still much to be done.

Another topic concerning olives' and olive oil's polar lipids is their positive impact on human nutrition and health, which has been little exploited [14,15]. Additionally, in recent years, polar lipids from olive-derived industrial by-products, such as olive seeds and olive pomace, have been studied as alternative sources of bioactive lipids. The new applications of polar lipids would favor the sustainable use of olive's industrial by-products and make them attractive from the biotechnological standpoint.

\section{Identification of Polar Lipids from Olives, Olive Oil, and Their Industrial By-Products}

The identification of polar lipids in olives and olive oil is a difficult task since they are minor components and include a broad range of lipid classes. Different analytical approaches have been used to unravel the polar lipidome of these matrices. The lipidomic workflows included lipid extraction, fractionation, analysis and quantification (Figure 1).

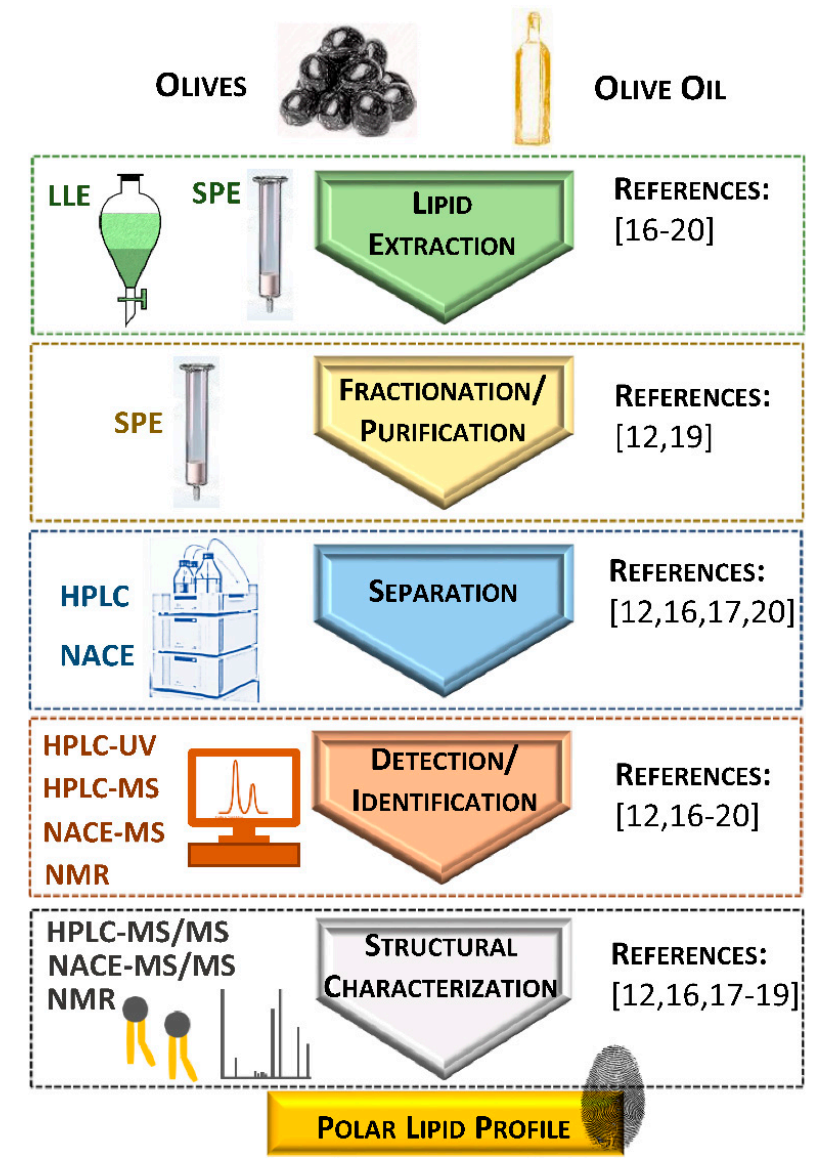

Figure 1. Schematic representation of the methodological approaches used for studying polar lipids from olives and olive oil. Abbreviations: HPLC, high-performance liquid chromatography; HPLC-MS, high-performance liquid chromatography coupled to mass spectrometry; HPLC-MS/MS, high-performance liquid chromatography coupled to tandem mass spectrometry; HPLC-UV, high-performance liquid chromatography with ultraviolet detector; LLE, liquid/liquid extraction; NACE, non-aqueous capillary electrophoresis; NACE-MS, non-aqueous capillary electrophoresis coupled to mass spectrometry; NACE-MS/MS, non-aqueous capillary electrophoresis coupled to tandem mass spectrometry; NMR, nuclear magnetic resonance; SPE, solid-phase extraction. 
Liquid/liquid extraction (LLE) has been used for extracting polar lipids from olives and olive oil. The most commonly used LLE methods were a modified Bligh and Dyer method [16], a modified Folch method [17] and a sequential LLE method developed by Galanos and Kapoulas [17-19]. Solid-phase extraction (SPE), using aminopropyl-bonded silica as sorbent, was recently used to obtain polar lipid-enriched fractions directly from olive oil [12]. There are other emerging extraction techniques that can be used for oil extraction from olives, such as ultrasound or microwave or $\mathrm{CO}_{2}$-assisted techniques, but these approaches have not yet been reported for the analysis of polar lipids in olives or olive oil.

After extraction, the total lipid extract can be fractionated to obtain polar lipid-enriched fractions or specific polar lipid classes. Polar lipid-enriched fractions were obtained using SPE cartridges with different stationary phases (silica and diol-bonded silica) after olive oil's LLE [19].

${ }^{31} \mathrm{P}$ nuclear magnetic resonance (NMR) spectroscopy [18] and non-aqueous capillary electrophoresis (NACE) coupled with MS [17] were used for the detection and characterization of the phospholipid classes of olive oil.

The separation of the polar lipid classes obtained from olive oil was carried out by high-performance liquid chromatography (HPLC) coupled to different detectors, as ultraviolet detectors (HPLC-UV) [20] or mass spectrometers (HPLC-MS) [12,16,19]. The structural characterization of the polar lipid molecules, namely the polar head and fatty acyl composition, has been achieved by using tandem MS (HPLC-MS/MS in [12,16,19] and NACE-MS/MS in [17]).

The analytical approaches used so far (Table 1) showed different results. In olive fruits, the polar lipidome has been studied in the oil extracted both from the pulp and the seed. Bianco et al. (1998) identified glycolipids in the olive pulp, namely digalactosyldiacylglycerols as DGDG(18:3/18:3) and DGDG(18:1/18:3) [20]. Montealegre et al. (2013) analyzed the glycerophospholipid profile of olive fruits from different Spanish cultivars and regions [17]. The glycerophospholipids identified in the olive pulp and in the seed included phosphatidic acid (PA), lyso-PA, phosphatidylethanolamine (PE), lyso-PE, phosphatidylcholine (PC), phosphatidylinositol (PI) and phosphatidylglycerol (PG) [17] (Figure 2).

Olive oil has been shown to possess several classes of glycerophospholipids (Figure 2), but the presence and amount of each class vary considerably among studies (Table 1). Authors found that the main glycerophospholipid class is PG [16], PE [17], PA [18], or lyso-PA [19]. In Greek VOOs, glycerophospholipids were identified and quantified by ${ }^{31} \mathrm{P}-\mathrm{NMR}$ [18]. PA, PI, and lyso-PA were the major classes identified, but PC, PE, and lyso-PI were also found. PG was only detected in one olive pomace oil that showed higher diversity and concentration in the glycerophospholipid classes: PA, lyso-PA, PI and lyso-PI [18]. The MS-based approaches used by other researchers also led to different results. The glycerophospholipid profile of a commercial Tunisian olive oil was composed by PG, PA, PI, PE, and PC (by descending order of abundance) [16]. In a monovarietal commercial olive oil from the Spanish cultivar Arbequina, the glycerophospholipid classes identified were, by descending order, PE, PG, PC, lyso-PE and lyso-PA [17]. The glycerophospholipid classes from an Italian VOO blend with Leccino, Frantoio, and Picholine cultivars were PG, PA, lyso-PA, PI, PC and lyso-PC [19]. Calvano et al. (2012) identified different molecular species of PC in one commercial olive oil [13]. Molecular species of PA, PE, PG, PC, and PI were identified in Portuguese commercial olive oils, as well as other lipid molecules not identified previously in this matrix [12]. Glycolipids as DGDG(18:3/18:3) and DGDG(18:3/18:1) were identified in one Italian olive oil [20]. Table 1 summarizes the main results of each of these works. All the molecular species of glycerophospholipids and glycolipids identified by the MS-based lipidomic approaches, both in olives and olive oil, are listed in Tables 2 and 3 , respectively.

The concentration of glycerophospholipids in olive oils has been estimated by measuring the total phosphorus amount [21] using reference methods. For absolute quantification authors used ${ }^{31}$ P-NMR spectroscopy [18] and HPLC-MS [19]. Glycerophospholipids in olive oil are in parts per million ( $\mathrm{mg} \mathrm{kg}^{-1}$ of olive oil): 21 to 124 [21]; 11 to 157 [18] and 3.29 to 8.25 [19]. 


\section{Analytical Challenges in Identifying Polar Lipids in Olives and Olive Oil}

The results provided by the identification and characterization of the mentioned studies are motivating but not comparable. A systematic analysis of polar lipids in these matrices has not been performed yet, and there are no official methods for their characterization.

There are several advantages of using HPLC-MS approaches. They allow a fast and reproducible analysis, in a short time-frame [16,17], with high sensitivity [19]. At the same time, it provides detailed structural information about the polar head and fatty acyl composition of each glycerophospholipid class, by the analysis and interpretation of the MS/MS data [16]. However, some analytical bottlenecks of this methodology include: chemical noise in the MS/MS spectra and unachievable MS/MS identification of the fatty acyl chains for all glycerophospholipids, due to their low amount in the samples [16]; absence of fragmentation data, possibly due to their low concentration and the complexity of the matrix [17]; and the need for further validation of quantification values with absolute quantitative methods [17].

In addition to MS-based approaches, NMR spectroscopy is a potentially valuable technique for analyzing phospholipids in olive oil [22]. Compared to HPLC-MS, NMR and specifically ${ }^{31}$ P-NMR, has higher selectivity, ease of performance and faster analysis. Another advantage of using ${ }^{31} \mathrm{P}-\mathrm{NMR}$ is that glycerophospholipids give a single signal in the spectrum, while different molecules of these lipids are characterized by specific resonance frequencies derived from their distinct chemical structures. As such, there is no need to separate the components in the sample before analysis [18], as in HPLC-MS. Even so, ${ }^{31} \mathrm{P}-\mathrm{NMR}$ high-resolution spectra were hampered by the formation of aggregates and electrostatic complexes with ions in solution [18]. The fatty acyl composition of the phospholipids could only be estimated since proton signals are common to the various fatty acyl chains attached to $s n-1$ and $s n-2$ positions of glycerol in the phospholipid molecules [23]. Long spectra acquisitions (one hour) were needed to achieve a reasonable signal to noise ratio, due to the low concentration of glycerophospholipids in olive oil [18]. The authors needed $100 \mathrm{~g}$ of olive oil to carry out the experiments and to obtain the glycerophospholipid profile, while others, using LC-MS/MS approaches, demanded $1 \mathrm{~g}$ [12] to $50 \mathrm{~g}$ [17]. Besides, the ${ }^{31} \mathrm{P}-\mathrm{NMR}$ approach cannot identify glycolipids in olive oil and these lipids also make up the polar lipid pool of this matrix $[12,20]$.

\section{The Importance of Studying Polar Lipids from Olives and Olive Oil}

\subsection{Authentication, Traceability, and Detection of Adulteration}

Olive oil's chemical composition depends on both geographical and botanical origin of olives. It also varies with pedo-climatic, environmental, agricultural and technological conditions, which gives rise to a unique product with distinct features. High-quality olive oils, as VOOs, have a specific chemical fingerprint, but it has been difficult to assign an identity that can differentiate VOOs from other olive oils. Consequently, the authenticity of VOOs can be at risk during the olive oil chain production, and ultimately, it may lead to fraud or adulteration. To date, it has not been possible to provide an identity to each olive oil.

Some research groups studied olive oil's polar lipids to address identity, traceability, and authenticity issues. A first approach based on the relative abundances of the glycerophospholipids allowed to distinguish the botanical and geographical origin of olive fruits. The olives samples used for the study were from different Spanish varieties (Empeltre, Lechín de Sevilla, and Arbequina) from the same region (Córdoba), and from the same variety (Arbequina) from different regions (Toledo, Córdoba and Jaén) [17]. There were variations on the relative abundance of the polar lipid classes identified in the seeds and in the pulp, and among different olive pulps from different cultivars. Some classes that were found in the pulp (lyso-PE and PE) were not detected in the respective seed and not all the classes were detected in all olive pulp samples. For instance, lyso-PA was not detected in Empeltre variety from Córdoba [17]. In another work, it was found that each olive oil seems to reveal a unique polar lipid profile [12], showing that each olive oil had a different PC profile and one olive 
oil had specific polar lipid molecular species, not detected in the other samples. These findings are a promising start for future research on olive oil's identity and traceability.

In the case of adulteration, it is possible to detect adulterated olive oil with levels as low as 1 to $5 \%$ of hazelnut oil, based on glycerophospholipids as biochemical markers [13]. This is a significant advantage since adulteration of extra $\mathrm{VOO}$ with hazelnut oil cannot be straightforwardly detected by well-established techniques because these oils have similar triacylglycerol, fatty acid, and sterol profiles [24].

Even though there are still methodological bottlenecks in studying polar lipids from olives and olive oil, these lipids are considered as new important biochemical markers. A phospholipid profile has been suggested to be included in a flowchart to detect the presence of a specific adulterant in olive oils [10].

\subsection{Nutrition and Health}

It has been widely acknowledged that olive oil's intake, either within the Mediterranean diet or alone, has a positive impact on human health $[25,26]$. Nevertheless, little is known about the bioactivity or health benefits of phospholipids and glycolipids from olives and olive oil. A few in vivo and in vitro studies revealed anti-cancer or cancer-preventative effects of food glycolipids [27-29], as well as anti-inflammatory effects in arthritis and osteoarthritis [27-30]. Olive fruits possess glycolipids (DGDG) in a concentration of $280 \mathrm{mg} \mathrm{kg}^{-1}$ [20], but their bioactivity remains to be studied. 
Table 1. Summary of the polar lipid classes identified and quantified in olives and olive oils in different studies.

\begin{tabular}{|c|c|c|c|c|c|}
\hline \multirow{2}{*}{ Reference } & \multicolumn{2}{|l|}{ Sampling } & \multicolumn{2}{|l|}{ Analysis } & \multirow[t]{2}{*}{ Polar Lipid Classes } \\
\hline & Type of Sample & Amount of Sample & Extraction & Method & \\
\hline [20] & $\begin{array}{l}\text { Olive fruit and olive oil from varieties Carolea and } \\
\text { Ottobratica, both from Calabria region (Italy) }\end{array}$ & $\begin{array}{l}\text { Olive fruit }(250 \mathrm{~g}) \text {; olive } \\
\text { oil }(10 \mathrm{~mL})\end{array}$ & $\begin{array}{l}\text { Glycosidic fraction in olive fruit: } \\
\text { ethanol and "charcoal method"; } \\
\text { glycosidic fraction in the aqueous } \\
\text { phase of olive oil: ethyl } \\
\text { acetate/dichloromethane (1:1 by } \\
\text { volume) and water }\end{array}$ & $\begin{array}{l}\text { HPLC-UV ( } \mu \text {-Bondapak } \\
\text { C18 column) }\end{array}$ & DGDG \\
\hline [16] & Tunisian commercial olive oil & Not said & Modified Bligh and Dyer method & $\begin{array}{l}\text { HPLC-MS/MS (diol } \\
\text { column) }\end{array}$ & $\begin{array}{c}\text { PG (63\%), PA (12\%), PI (11\%), PE (9\%), } \\
\text { PC (5\%) }\end{array}$ \\
\hline [18] & $\begin{array}{l}\text { Greek virgin olive oil, refined olive oil and olive } \\
\text { pomace oil from local cooperatives ( } 7 \text { regions and } \\
5 \text { cultivars) }\end{array}$ & $100 \mathrm{~g}$ & $\begin{array}{l}\text { According to Galanos and Kapoulas } \\
\qquad(1962)\end{array}$ & ${ }^{31} \mathrm{P}-\mathrm{NMR}$ & $\begin{array}{l}\text { PA, lyso-PA, lyso-PI, PI, PG (PG only in } \\
\text { pomace oil), PC and PE (these two only } \\
\text { in virgin olive oil). }\end{array}$ \\
\hline \multirow[t]{2}{*}{ [17] } & \multirow{2}{*}{$\begin{array}{l}\text { Olive pulp and olive stone from Spanish Arbequina } \\
\text { variety from three geographical regions (Córdoba, } \\
\text { Jaén, and Toledo) and two Spanish varieties (Empeltre } \\
\text { and Lechín de Sevilla) from the same region } \\
\text { (Córdoba); commercial monovarietal extra virgin } \\
\text { olive oil from Arbequina variety }\end{array}$} & \multirow[t]{2}{*}{$\begin{array}{l}\text { Olive pulp or stone }(2.5 \mathrm{~g}) \\
\text { olive oil }(50 \mathrm{~g})\end{array}$} & \multirow[t]{2}{*}{$\begin{array}{l}\text { PL from olive pulp and stone: } \\
\text { modified Folch method; PL from olive } \\
\text { oil: LLE according to Galanos and } \\
\text { Kapoulas (1962) }\end{array}$} & \multirow[t]{2}{*}{$\begin{array}{l}\text { NACE-ESI-MS and } \\
\text { MS/MS }\end{array}$} & $\begin{array}{c}\text { Olives (stone and pulp studied } \\
\text { independently): PA (54-82\%), PE } \\
(4-16 \%), \text { PC (3-9\%), lyso-PE } \\
(1.3-18 \%), \text { PI }(4.4-8 \%), \text { PG } \\
(3.7-6.3 \%), \text { and lyso-PA }(0.1-0.2 \%) \text {. }\end{array}$ \\
\hline & & & & & $\begin{array}{l}\text { Olive oil: PE }(42 \%), \text { PG }(38 \%), \text { PC } \\
(15 \%) \text {, lyso-PE }(4.5 \%) \text {, and lyso-PA } \\
(0.2 \%)\end{array}$ \\
\hline [19] & $\begin{array}{l}\text { Italian olive oil blend (Leccino, Frantoio and Picholine } \\
\text { varieties) from a local mill of Emilia Romagna } \\
\text { region (Italy) }\end{array}$ & $100 \mathrm{~g}$ for LLE; $40 \mathrm{~g}$ for SPE & $\begin{array}{l}\text { LLE according to Galanos and } \\
\text { Kapoulas (1962) followed by SPE (diol } \\
\text { and silica). PL eluted with methanol } \\
\text { and chloroform/methanol/water (3:5:2 } \\
\text { by volume) }\end{array}$ & $\begin{array}{l}\text { HPLC-ESI-qTOF-MS } \\
\text { (HILIC column) }\end{array}$ & $\begin{array}{c}\text { Diol extracted veiled extra virgin olive } \\
\left.\text { oil (mg kg }{ }^{-1}\right) \text { : lyso-PA (4.23), lyso-PC } \\
(1.21), \text { PI (1.03), PC (0.90), PA (0.81), PG } \\
\text { (0.07). Crystallized veiled virgin olive } \\
\left.\text { oil (mg kg }{ }^{-1}\right) \text { : lyso-PA (1.15), lyso-PC } \\
(0.87), \text { PC (0.74), PI (0.48), PA (0.14) }\end{array}$ \\
\hline [12] & $\begin{array}{l}\text { Portuguese commercial extra virgin and virgin } \\
\text { olive oils }\end{array}$ & $1 \mathrm{~g}$ & $\begin{array}{l}\text { PL extracted by SPE (aminopropyl } \\
\text { columns) and eluted with acetonitrile: } \\
\text { ammonium hydroxide (95:5 by } \\
\text { volume) }\end{array}$ & $\begin{array}{l}\text { HPLC-ESI-ion } \\
\text { trap-MS/MS (HILIC } \\
\text { column) }\end{array}$ & $\begin{array}{c}\text { PA, PE, PG, PC, PI, SQDG, SQMG, } \\
\text { DGTS }\end{array}$ \\
\hline
\end{tabular}

Legend: DGDG, digalactosyldiacylglycerol; DGTS, diacylglyceryl-N,N,N-trimethylhomoserine; HILIC, hydrophilic interaction liquid chromatography; HILIC-ESI-MS/MS, hydrophilic interaction liquid chromatography coupled to electrospray ionization tandem mass spectrometry; HPLC, high-performance liquid chromatography; HPLC-ESI-qTOF-MS, high-performance liquid chromatography coupled to electrospray ionization-quadrupole time-of-flight mass spectrometry; HPLC-UV, high-performance liquid chromatography with ultraviolet detector; HPLC-MS/MS, high-performance liquid-chromatography coupled to tandem mass spectrometry; LLE, liquid/liquid extraction; MS/MS, tandem mass spectrometry; NACE-ESI-MS, non-aqueous capillary electrophoresis coupled to electrospray ionization mass spectrometry; NMR, nuclear magnetic resonance; PA, phosphatidic acid; PC, phosphatidylcholine; PE, phosphatidylethanolamine; PG, phosphatidylglycerol; PI, phosphatidylinositol; PL, polar lipid; SPE, solid-phase extraction; SQDG, sulfoquinovosyldiacylglycerol; SQMG, sulfoquinovosylmonoacylglycerol. 


\section{Glycerophospholipids}

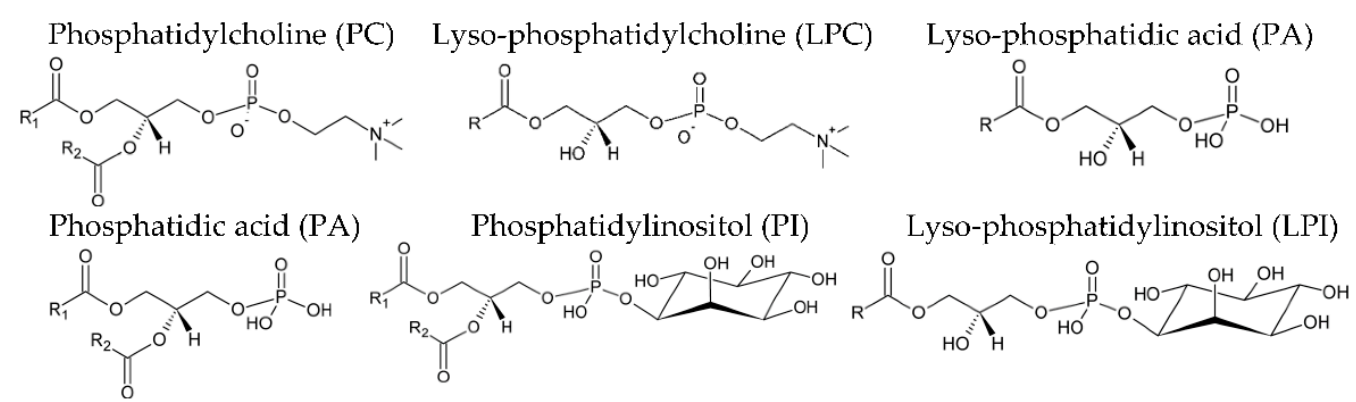

Lyso-phosphatidylethanolamine (LPE) Phosphatidylethanolamine (PE) Phosphatidylglycerol (PG)<smiles>[R]C(=O)OC[C@@H](O)COP(=O)(O)OCCN</smiles>

Digalactosyldiacylglycerol (DGDG)<smiles>[R]C(=O)OC[C@@H]([2H])OC[C@H](O)OP(=O)(O)OCCN</smiles><smiles>[R]C(=O)OC[C@@H]([2H])COP(=O)(O)OC[C@H](O)CO</smiles>

Glycolipids

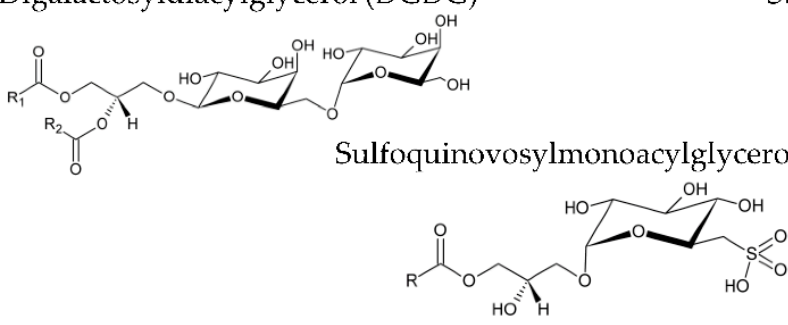

Sulfoquinovosyldiacylglycerol (SQDG)

Betaine lipids

Diacylglyceryl- $N, N, N$-trimethyl homoserine (DGTS)<smiles>CC(C)(C)NC(=O)CCCOCCC(N)C(=O)O</smiles>

Figure 2. Chemical structures of the classes of glycerophospholipids and glycolipids identified in olives and olive oil. Polar lipids include a broad range of molecules. Phospholipids are divided into two main classes depending on whether they contain glycerol (glycerophospholipids) or a sphingosyl (sphingophospholipids) backbone. Glycerophospholipids, besides the glycerol backbone, contain a polar phosphorus moiety. They derive mainly from sn-1,2-diacylglycerols and, thus, contain structures that are based on 3-sn-phosphatidic acid [31]. These lipids are grouped into classes based on the composition of their polar head group that is attached to the phosphate residue in $s n-3$ position. The polar head may be an amino acid, an amino-alcohol, a carbohydrate or another functional moiety. Each head group class is further differentiated into subclasses based on the $s n-1$ and $s n-2$ substituents on the glycerol backbone [31]. Glycolipids also include a wide variety of structures. These structures consist in acylglycerols (in the case of glycosylglycerides and sulfolipids) joined to a carbohydrate moiety by a glycosidic linkage at the $s n-3$ position [31]. Betaine lipids are ether-linked glycerolipids containing a betaine moiety. These lipids contain a polar group linked by an ether bond at the $s n-3$ position of the glycerol moiety, with the fatty acids esterified in the $s n-1$ and $s n-2$ positions [31]. 1,2-diacylglyceryl-3-O-4'-(N,N,N-trimethyl)-homoserine (DGTS) have been commonly found in lower plants, algae, fungi, and bacteria [32]. R, R1, and R2 represent fatty acyl chains.

Some studies evaluated the bioactive properties of the polar lipid fraction of olive oil and olive pomace and revealed that they possess anti-thrombotic and anti-atherosclerotic activities by inhibiting platelet aggregation. This inhibition was assigned to inhibitors or antagonists of platelet aggregation factor (PAF) [15], that were further identified in olive oil as a glycerol glycolipid [14]. Olive pomace's polar lipids also inhibited platelet aggregation in vitro [15]. The most potent antagonist was identified as a glycerylether-sn-2-acetyl glycolipid, structurally similar to the one previously identified in olive oil [15]. Olive pomace's polar lipids revealed a higher potency than olive oil's polar lipids in inhibiting 
PAF-induced aggregation, as well as specific PAF binding [15]. Thus, olive pomace's polar lipids were suggested to be used as a dietary supplement in the prevention of the progression of atherogenesis [33].

There is some scientific evidence that the polar lipid fraction from olive oil and olive pomace possess anti-thrombotic and anti-atherosclerotic activity mediated by PAF. Nevertheless, more studies are needed to elucidate the chemical structure of the bioactive lipids to understand the mechanisms of action and to determine the concentration of these compounds in olive oil or olive-pomace to observe an in vivo effect in human beings.

\section{Potential Biotechnological Uses of Polar Lipids from Olives' and Olive Oil's Industrial By-Products}

Olive oil mills and pitted table olives' producing industries generate several by-products, such as olive pomace and olive stones. These by-products can be recovered to create novel value-added products. In the case of polar lipids, their concentration is tens to hundred times higher in olive pomace oil [18] and olive seed oil [34], comparatively to olive oil [18,21]. Thus, polar lipids from olive pomace and olive seeds have been regarded as potentially useful from the nutritional and biotechnological standpoints and have been suggested for several novel industrial applications.

Olive pomace was proposed as the new promising lipid source for the sustainable production of animal feeds, namely functional fish feeds, feed for aquaculture fish and as an ingredient for inclusion in animal feedstocks [35]. Olive pomace after stoning has been extensively studied in mammal's species as feed integration for improving the nutritional and nutraceutical properties of their meat as well as their milk and derived cheese [36-40]. Other studies carried out on fish species revealed that polar lipids from olive pomace oil [41] provide high nutritional value for fish feed [35] and increase fish cardio-protective properties [42]. The later studies carried out on fish fed with fish oil containing $4 \%$ of olive pomace indicated that the lipid fractions containing polar lipids had inhibitory activity against PAF-induced platelet aggregation [42]. Further research is needed on the bioactive properties of olive pomace and olive pomace oil for animal feed purposes and to identify the molecules within the polar lipid fraction responsible for such activity.

Other residues resulting from table olives' production are the stones that contain the seeds. The economic potentialities of olive seeds and olive seed oil have been explored in the last few years, primarily by the industry [43] 
Table 2. List of glycerophospholipid molecular species identified in olives and olive oil through mass spectrometry-based lipidomic approaches.

\begin{tabular}{|c|c|c|c|c|c|c|c|c|c|}
\hline Reference & $\begin{array}{l}\text { Olive Fruit } \\
\text { and/or Oil }\end{array}$ & $\begin{array}{c}\text { Molecular } \\
\text { Species (C:N) }\end{array}$ & Fatty Acyl Chains (C:N) & $\begin{array}{c}{[\mathrm{M}+\mathrm{H}]^{+}} \\
\mathrm{m} / \mathrm{z}\end{array}$ & $\begin{array}{c}{[\mathrm{M}+\mathrm{Na}]^{+}} \\
\mathrm{m} / \mathrm{z}\end{array}$ & $\begin{array}{c}{[\mathrm{M}+\mathrm{K}]^{+}} \\
\mathrm{m} / \mathrm{z}\end{array}$ & $\begin{array}{c}{[\mathrm{M}-\mathrm{H}]^{-}} \\
m / z\end{array}$ & {$\left[\begin{array}{c}\mathrm{M}+\mathrm{HCOO}^{-} \\
\mathrm{m} / z\end{array}\right.$} & $\begin{array}{c}{\left[\mathrm{M}+\underset{m / z}{\left.\mathrm{CH}_{3} \mathrm{COO}\right]^{-}}\right.} \\
\end{array}$ \\
\hline [19] & Oil & LPA(16:1) & $16: 1$ & & & & 407.2 & & \\
\hline [19] & Oil & LPA(18:1) & $18: 1$ & & & & 435.3 & & \\
\hline [19] & Oil & LPC $(18: 1)$ & $18: 1$ & & & & & 566.3 & \\
\hline [19] & Oil & LPC $(18: 2)$ & $18: 2$ & & & & & 564.3 & \\
\hline [19] & Oil & PA(34:1) & 16:1/18:0 & & & & 673.5 & & \\
\hline [17] & Fruit & PA(36:0) & 18:0/18:0 & & & & 703 & & \\
\hline [17] & Fruit & PA(36:1) & 18:1/18:0 & & & & 701 & & \\
\hline [19] & Oil & $\mathrm{PA}(36: 2)$ & 18:0/18:2 & & & & 699.5 & & \\
\hline [12] & Oil & PA(38:2) & $18: 1 / 20: 1$ and $18: 0 / 20: 2$ and $18: 2 / 20: 0$ & & & & 727.2 & & \\
\hline$[12]$ & Oil & PC $(32: 0)$ & $16: 0 / 16: 0$ & 734.5 & & & & & \\
\hline [12] & Oil & PC(32:1) & $16: 0 / 16: 1$ and $14: 0 / 18: 1$ & 732.4 & 754.5 & & & & \\
\hline [12] & Oil & $\mathrm{PC}(32: 2)$ & $16: 1 / 16: 1$ and $14: 1 / 18: 1$ & 730.4 & 752.4 & & & & \\
\hline$[12,19]$ & Oil & PC $(34: 1)$ & $\begin{array}{c}16: 0 / 18: 1 \text { and } 16: 1 / 18: 0 \text { and } 14: 0 / 20: 1 \\
\text { and } 14: 1 / 20: 0\end{array}$ & 760.5 & 782.5 & 798.5 & & 804.6 & 818.2 \\
\hline$[12,19]$ & Oil & $\mathrm{PC}(34: 2)$ & $16: 1 / 18: 1$ or $16: 0 / 18: 2$ and $14: 0 / 20: 2$ & 758.5 & 780.5 & 796.5 & & 802.6 & \\
\hline [12] & Oil & $\mathrm{PC}(34: 3)$ & $\begin{array}{c}16: 1 / 18: 2 \text { and } 14: 0 / 20: 3,16: 0 / 18: 3 \text { and } \\
16: 1 / 18: 2\end{array}$ & 756.5 & 778.5 & 794.5 & & & \\
\hline$[12,17]$ & Oil and fruit & $\operatorname{PC}(36: 1)$ & $18: 0 / 18: 1$ & 788.5 & & 826.5 & & & \\
\hline [12] & Oil & $\mathrm{PC}(36: 2)$ & $\begin{array}{c}18: 1 / 18: 1 \text { or } 18: 0 / 18: 2 \text { or } 16: 0 / 20: 2 \text { or } \\
16: 1 / 20: 1\end{array}$ & 786.5 & 808.6 & 824.5 & & & \\
\hline [17] & Fruit & $\mathrm{PC}(38: 5)$ & $20: 2 / 18: 3$ & 809 & & & & & \\
\hline [12] & Oil & $\mathrm{PC}(\mathrm{O}-34: 2)$ & $\mathrm{O}-16: 0 / 18: 2$ and $\mathrm{O}-16: 1 / 18: 1$ & & 766.4 & & & & \\
\hline [12] & Oil & $\mathrm{PC}(\mathrm{O}-34: 3)$ & O-16:0/18:3 & & 764.4 & & & & \\
\hline [12] & Oil & $\mathrm{PC}(\mathrm{O}-36: 1)$ & $O-18: 1 / 18: 0$ and $O-16: 0 / 20: 1$ & & 796.6 & & & & \\
\hline [12] & Oil & $\mathrm{PC}(\mathrm{O}-36: 3)$ & $\mathrm{O}-18: 0 / 18: 3$ and $\mathrm{O}-18: 1 / 18: 2$ & & 792.4 & & & & \\
\hline [12] & Oil & $\mathrm{PE}(34: 1)$ & $16: 0 / 18: 1$ and $16: 1 / 18: 0$ & & & & 716.3 & & \\
\hline [17] & Fruit & $\mathrm{PE}(38: 2)$ & 20:2/18:0 & 773 & & & & & \\
\hline [12] & Oil & PG(32:0) & $16: 0 / 16: 0$ & & & & 721.5 & & \\
\hline [17] & Fruit & PG(34:0) & $16: 0 / 18: 0$ & & & & 749 & & \\
\hline$[12,17,19]$ & Fruit and oil & PG(34:1) & $16: 0 / 18: 1$ & & 771.5 & & 747.5 & & \\
\hline [17] & Fruit & PG(36:1) & $18: 1 / 18: 0$ & & & & 775 & & \\
\hline$[17]$ & Fruit & $\begin{array}{l}\text { PG(36:2), } \\
\text { PA(42:7) }\end{array}$ & $\operatorname{PG}(18: 1 / 18: 1)$ & & 797.5 & 813.5 & 773 & & \\
\hline$[17,19]$ & Fruit and oil & PI(34:0) & 16:0/18:0 & & & & 837.6 & & \\
\hline
\end{tabular}


Table 2. Cont.

\begin{tabular}{|c|c|c|c|c|c|c|c|c|c|}
\hline Reference & $\begin{array}{l}\text { Olive Fruit } \\
\text { and/or Oil }\end{array}$ & $\begin{array}{c}\text { Molecular } \\
\text { Species (C:N) }\end{array}$ & Fatty Acyl Chains (C:N) & $\begin{array}{c}{[\mathrm{M}+\mathrm{H}]^{+}} \\
\mathrm{m} / \mathrm{z}\end{array}$ & $\begin{array}{c}{[\mathrm{M}+\mathrm{Na}]^{+}} \\
\mathrm{m} / \mathrm{z}\end{array}$ & $\begin{array}{c}{[\mathrm{M}+\mathrm{K}]^{+}} \\
\mathrm{m} / \mathrm{z}\end{array}$ & $\begin{array}{c}{[\mathbf{M}-\mathbf{H}]^{-}} \\
m / z\end{array}$ & $\begin{array}{c}{\left[\mathrm{M}+\underset{\mathrm{m} / z}{\mathrm{HCOO}]^{-}}\right.} \\
\text {- }\end{array}$ & $\begin{array}{c}{\left[\mathrm{M}+\mathrm{CH}_{3} \mathrm{COO}\right]^{-}} \\
m / z\end{array}$ \\
\hline$[17,19]$ & Oil and fruit & $\mathrm{PI}(34: 1)$ & $16: 0 / 18: 1$ & & & & 835.6 & & \\
\hline [12] & Oil & $\mathrm{PI}(34: 1-\mathrm{OH})$ & 16:0/18:1-OH & & & & 851.4 & & \\
\hline [19] & Oil and fruit & $\mathrm{PI}(34: 2)$ & $16: 1 / 18: 1$ and $16: 0 / 18: 2$ & & & & 833.6 & & \\
\hline [19] & Oil and fruit & $\mathrm{PI}(34: 3)$ & $16: 1 / 18: 2$ & & & & 831.5 & & \\
\hline [17] & Fruit & $\mathrm{PI}(36: 1)$ & 18:0/18:1 & & & & 863 & & \\
\hline$[12,17]$ & Oil and fruit & $\mathrm{PI}(36: 3)$ & $18: 2 / 18: 1$ & & & & 859.2 & & \\
\hline
\end{tabular}

$(\mathrm{C}: \mathrm{N})$ indicates the number of carbon atoms $(\mathrm{C})$ and double bonds $(\mathrm{N})$ in the fatty acyl side chains. Legend: LPA, lyso-phosphatidic acid; LPC, lyso-phosphatidylcholine; PA, phosphatidic acid; PC, phosphatidylcholine; PE, phosphatidylethanolamine; PG, phosphatidylglycerol; PI, phosphatidylinositol.

Table 3. List of glycoglycerolipid and betaine lipid molecular species identified in olive oil through mass spectrometry-based lipidomic approaches.

\begin{tabular}{|c|c|c|c|c|}
\hline Reference & Molecular Species (C:N) & Fatty Acyl Chains (C:N) & {$[\mathbf{M}-\mathbf{H}]^{-} m / z$} & {$[\mathbf{M}+\mathbf{H}]^{+} m / z$} \\
\hline \multirow{10}{*}{ [12] } & SQDG (34:1) & $16: 0 / 18: 1$ & 819.4 & \\
\hline & SQDG (35:0) or SQDG(34:1-OH) & $16: 0 / 19: 0$ or $16: 0 / 18: 1-\mathrm{OH}$ & 835.5 & \\
\hline & SQDG(28:0) & $14: 0 / 14: 0$ and $12: 0 / 16: 0$ & 737.1 & \\
\hline & SQDDG(30:0) & $14: 0 / 16: 0$ & 765.4 & \\
\hline & SQDG(32:0) & $16: 0 / 16: 0$ and $14: 0 / 18: 0$ & 793.5 & \\
\hline & SQDG(32:1-OH) & $14: 0 / 18: 1-\mathrm{OH}$ & 807.5 & \\
\hline & SQDG(34:2-OH) & $16: 0 / 18: 2-\mathrm{OH}$ & 833.5 & \\
\hline & SQMG(14:0) & $14: 0$ & 527.2 & \\
\hline & SQMG(16:0) & $16: 0$ & 555.3 & \\
\hline & DGTS(34:1) & $16: 0 / 18: 1$ & & 738.5 \\
\hline
\end{tabular}

$(\mathrm{C}: \mathrm{N})$ indicates the number of carbon atoms $(\mathrm{C})$ and double bonds $(\mathrm{N})$ in the fatty acyl side chains. Legend: DGTS, diacylglyceryl-N,N,N-trimethylhomoserine; SQDG, sulfoquinovosyldiacylglycerol; SQMG, sulfoquinovosylmonoacylglycerol. 
Olive seed oil has $0.1 \%$ of phospholipids [34] and may have diverse technological uses in the soap, cosmetics and pharmaceutic industries [34]. Phospholipids from olive seeds can also be used for lecithin production in the agri-food industry [34]. Food derived phospholipids have several biomedical applications, for instance, as emulsifiers in pharmaceuticals and for the preparation of liposomes for cosmetics and drug delivery [44,45].

The potential biotechnological applications of the olive-derived by-products highlight the valuable alternatives that underlie the table olive's and olive oil's industries. However, more research is needed to characterize the polar lipidome, its health benefits and the cost-benefit of being extracted from these by-products.

\section{Conclusions and Future Perspectives}

Glycerophospholipids, glycolipids and betaine lipids were identified in olives and olive oil, but the identification of the lipidome of these foodstuffs is far from being fully covered. Distinct analytical approaches have been carried out to isolate and characterize the polar lipidome from these matrices, but those relying on NMR and MS have been the most successful. The diversity of polar lipid classes, the number of molecular species, and their ability to provide a molecular fingerprint for olives and olive oil claims for further research to achieve a standardized methodology for polar lipid identification. The study of polar lipids from olives and olive oil is essential for providing new insights into their quality, identity, authenticity, and traceability. The identification of polar lipids using the most modern technologies, as mass spectrometry coupled with liquid chromatography in a lipidomic approach, represent the most promising methodology to fulfill that goal. Simultaneously, it is also an innovative research opportunity in this field, as it can bring new inputs to the identity of these food matrices and their recognition as valuable components with health benefits. Few studies reported that polar lipids from olive oil and olive pomace possess bioactive properties, but this research field is still in its infancy. Polar lipids from olive pomace and olive seeds are being envisioned as promising ingredients to be recovered from olives' and olive oil's industrial processing for several biotechnological uses (Figure 3). Additionally, more information is needed on the polar lipidome of olive-derived industrial by-products, namely olive pomace, olive seeds, and their oils, to promote their recycling and reuse. Based on their polar lipids, novel value-added products and formulations can be conceived as important sources of components with biological activity. The wide range of biotechnological applications for these lipids recovered from olive's and olive oils' by-products include the feed, pharmaceutical, nutraceutical and dermocosmetic industries. Therefore, further investigation of the polar lipidome will foster the knowledge, valorization and sustainable use of these natural resources.

Importance of polar lipids from olives and olive oil

\begin{tabular}{l} 
Identity \\
- Each olive oil reveals a unique \\
polar lipid fingerprint \\
\multicolumn{1}{c}{ Traceability } \\
- Different phospholipid profiles are \\
observed for olives and olive oils \\
with distinct botanical and \\
geographical origins \\
Detection of adulteration \\
- Adulteration of olive oil with 1 to \\
$5 \%$ of hazelnut oil can be detected \\
by using phospholipid markers
\end{tabular}
activities bioactive molecules as dietary supplement
Valuing olive-derived industrial by-products

\section{Nutrition and health}

- Polar lipid fractions of olive oil and olive pomace have in vitro antithrombotic and anti-atherosclerotic

- Glycolipids were identified as the

- Polar lipids from olive oil and olive pomace are suggested as functional ingredients to be used

- Are used as animal feedstocks
ingredient, for functional fish feeds
and feed for aquaculture fish
- Polar lipids provide high nutritional
value and increase fish cardio-
protective properties
Olive seeds and olive seed oil
- Have many technological uses in
the agri-food, nutraceutic,
dermocosmetic and pharma
industries based on their polar
lipid content

Figure 3. Resume on the importance of polar lipids from olives, olive oil, and their by-products. 
Author Contributions: E.A. reviewed the literature and wrote the manuscript. M.R.M.D. and P.D. contributed to the design of the work, read and revised the manuscript. All authors read and approved the final manuscript.

Funding: The authors are thankful for the financial support from Fundação para a Ciência e a Tecnologia (FCT) and Portugal 2020 to the Portuguese Mass Spectrometry Network (LISBOA-01-0145-FEDER-402-022125). The authors thank to FCT/MEC for the financial support to the QOPNA research Unit (FCT UID/QUI/00062/2013), through national funds and where applicable co-financed by the FEDER, within the PT2020 Partnership Agreement. Thanks are also due for the financial support to CESAM (UID/AMB/50017-POCI-01-0145-FEDER-007638), to FCT/MCTES through national funds (PIDDAC), and the co-funding by the FEDER, within the PT2020 Partnership Agreement and Compete 2020. Eliana Alves thanks FCT for her post-doc fellowship (SFRH/BPD/109323/2015).

Conflicts of Interest: The authors declare no conflict of interest. The founding sponsors had no role in the design of the study; in the collection, analyses, or interpretation of data; in the writing of the manuscript, and in the decision to publish the results.

\section{References}

1. International Olive Council. World Olive Oil Figures. Available online: http://www.internationaloliveoil. org/estaticos/view /131-world-olive-oil-figures (accessed on 18 December 2017).

2. Boskou, D. 1-Olive oil: Properties and processing for use in food. In Specialty Oils and Fats in Food and Nutrition, 1st ed.; Talbot, G., Ed.; Woodhead: Cambridge, UK, 2015; pp. 3-38, ISBN 9781782423768.

3. Schwingshackl, L.; Hoffmann, G. Monounsaturated fatty acids and risk of cardiovascular disease: Synopsis of the evidence available from systematic reviews and meta-analyses. Nutrients 2012, 4, 1989-2007. [CrossRef] [PubMed]

4. Campestre, C.; Angelini, G.; Gasbarri, C.; Angerosa, F. The compounds responsible for the sensory profile in monovarietal virgin olive oils. Molecules 2017, 22, 1833. [CrossRef] [PubMed]

5. Servili, M.; Esposto, S.; Fabiani, R.; Urbani, S.; Taticchi, A.; Mariucci, F.; Selvaggini, R.; Montedoro, G. Phenolic compounds in olive oil: Antioxidant, health and organoleptic activities according to their chemical structure. Inflammopharmacology 2009, 17, 76-84. [CrossRef] [PubMed]

6. Aparicio, R.; Conte, L.S.; Fiebig, H.-J. Chapter 16. Olive oil authentication. In Handbook of Olive Oil: Analysis and Properties; Aparicio, R., Harwood, J., Eds.; Springer: Boston, MA, USA, 2013; pp. 589-5654, ISBN 978-1-4614-7777-8.

7. Perri, E.; Benincasa, C.; Muzzalupo, I. Chapter 13. Olive oil traceability. In Olive Germplasm-the Olive Cultivation, Table Olive and Olive Oil Industry in Italy; Muzzalupo, I., Ed.; InTechOpen: London, UK, 2012; pp. 265-286, ISBN 978-953-51-0883-2.

8. Montealegre, C.; Marina Alegre, M.L.; García-Ruiz, C. Traceability markers to the botanical origin in olive oils. J. Agric. Food Chem. 2010, 58, 28-38. [CrossRef] [PubMed]

9. Aparicio, R.; Morales, M.T.; Aparicio-Ruiz, R.; Tena, N.; García-González, D.L. Authenticity of olive oil: Mapping and comparing official methods and promising alternatives. Food Res. Int. 2013, 54, 2025-2038. [CrossRef]

10. Gallina Toschi, T.; Bendini, A.; Lozano-Sánchez, J.; Segura-Carretero, A.; Conte, L. Misdescription of edible oils: Flowcharts of analytical choices in a forensic view. Eur. J. Lipid Sci. Technol. 2013, 115, 1205-1223. [CrossRef]

11. Bajoub, A.; Bendini, A.; Fernández-Gutiérrez, A.; Carrasco-Pancorbo, A. Olive oil authentication: A comparative analysis of regulatory frameworks with especial emphasis on quality and authenticity indices, and recent analytical techniques developed for their assessment. A review. Crit. Rev. Food Sci. Nutr. 2018, 58, 832-857. [CrossRef] [PubMed]

12. Alves, E.; Melo, T.; Rey, F.; Moreira, A.S.; Domingues, P.; Domingues, M.R. Polar lipid profiling of olive oils as a useful tool in helping to decipher their unique fingerprint. LWT Food Sci. Technol. 2016, 74, 371-377. [CrossRef]

13. Calvano, C.D.; De Ceglie, C.; D'Accolti, L.; Zambonin, C.G. MALDI-TOF mass spectrometry detection of extra-virgin olive oil adulteration with hazelnut oil by analysis of phospholipids using an ionic liquid as matrix and extraction solvent. Food Chem. 2012, 134, 1192-1198. [CrossRef] [PubMed]

14. Karantonis, H.C.; Antonopoulou, S.; Demopoulos, C.A. Antithrombotic lipid minor constituents from vegetable oils. Comparison between olive oils and others. J. Agric. Food Chem. 2002, 50, 1150-1160. [CrossRef] [PubMed] 
15. Tsantila, N.; Karantonis, H.C.; Perrea, D.N.; Theocharis, S.E.; Iliopoulos, D.G.; Antonopoulou, S.; Demopoulos, C.A. Antithrombotic and antiatherosclerotic properties of olive oil and olive pomace polar extracts in rabbits. Med. Inflamm. 2007, 2007, 11. [CrossRef] [PubMed]

16. Boukhchina, S.; Sebai, K.; Cherif, A.; Kallel, H.; Mayer, P.M. Identification of glycerophospholipids in rapeseed, olive, almond, and sunflower oils by LC-MS and LC-MS-MS. Can. J. Chem. 2004, 82, 1210-1215. [CrossRef]

17. Montealegre, C.; Sanchez-Hernandez, L.; Crego, A.; Marina, M. Determination and characterization of glycerophospholipids in olive fruit and oil by nonaqueous capillary electrophoresis with electrospray-mass spectrometric detection. J. Agric. Food Chem. 2013, 61, 1823-1832. [CrossRef] [PubMed]

18. Hatzakis, E.; Koidis, A.; Boskou, D.; Dais, P. Determination of phospholipids in olive oil by ${ }^{31}$ P-NMR spectroscopy. J. Agric. Food Chem. 2008, 56, 6232-6240. [CrossRef] [PubMed]

19. Verardo, V.; Gómez-Caravaca, A.; Montealegre, C.; Segura-Carretero, A.; Caboni, M.; Fernández-Gutiérrez, A.; Bendini, A. Optimization of a solid phase extraction method and hydrophilic interaction liquid chromatography coupled to mass spectrometry for the determination of phospholipids in virgin olive oil. Food Res. Int. 2013, 54, 2083-2090. [CrossRef]

20. Bianco, A.; Mazzei, R.A.; Melchioni, C.; Scarpati, M.L.; Romeo, G.; Uccella, N. Microcomponents of olive oil. Part II: Digalactosyldiacylglycerols from Olea europaea. Food Chem. 1998, 62, 343-346. [CrossRef]

21. Koidis, A.; Boskou, D. The contents of proteins and phospholipids in cloudy (veiled) virgin olive oils. Eur. J. Lipid Sci. Technol. 2006, 108, 323-328. [CrossRef]

22. Dais, P.; Hatzakis, E. Quality assessment and authentication of virgin olive oil by NMR spectroscopy: A critical review. Anal. Chim. Acta 2013, 765, 1-27. [CrossRef] [PubMed]

23. Vigli, G.; Philippidis, A.; Spyros, A.; Dais, P. Classification of edible oils by employing ${ }^{31} \mathrm{P}$ and ${ }^{1} \mathrm{H}$ NMR spectroscopy in combination with multivariate statistical analysis. A proposal for the detection of seed oil adulteration in virgin olive oils. J. Agric. Food Chem. 2003, 51, 5715-5722. [CrossRef] [PubMed]

24. Arlorio, M.; Coisson, J.D.; Bordiga, M.; Travaglia, F.; Garino, C.; Zuidmeer, L.; Van Ree, R.; Giuffrida, M.G.; Conti, A.; Martelli, A. Olive oil adulterated with hazelnut oils: Simulation to identify possible risks to allergic consumers. Food Addit. Contam. 2010, 27, 11-18. [CrossRef] [PubMed]

25. Buckland, G.; Gonzalez, C.A. The role of olive oil in disease prevention: A focus on the recent epidemiological evidence from cohort studies and dietary intervention trials. Br. J. Nutr. 2015, 113, S94-S101. [CrossRef] [PubMed]

26. Covas, M.-I.; de la Torre, R.; Fitó, M. Virgin olive oil: A key food for cardiovascular risk protection. Br. J. Nutr. 2015, 113, S19-S28. [CrossRef] [PubMed]

27. Hou, C.-C.; Chen, Y.-P.; Wu, J.-H.; Huang, C.-C.; Wang, S.-Y.; Yang, N.-S.; Shyur, L.-F. A galactolipid possesses novel cancer chemopreventive effects by suppressing inflammatory mediators and mouse b16 melanoma. Cancer Res. 2007, 67, 6907-6915. [CrossRef] [PubMed]

28. Larsen, E.; Christensen, L.P. Common vegetables and fruits as a source of 1,2-di-O- $\alpha$-linolenoyl-3-O- $\beta$-Dgalactopyranosyl-sn-glycerol, a potential anti-inflammatory and antitumor agent. J. Food Lipids 2007, 14, 272-279. [CrossRef]

29. Rong, W.; Furumoto, T.; Motoyama, K.; Okazaki, K.; Kondo, A.; Fukui, H. Possible antitumor promoters in Spinacia oleracea (spinach) and comparison of their contents among cultivars. Biosci. Biotechnol. Biochem. 2002, 66, 248-254. [CrossRef]

30. Larsen, E.; Kharazmi, A.; Christensen, L.P.; Christensen, S.B. An antiinflammatory galactolipid from rose hip (Rosa canina) that inhibits chemotaxis of human peripheral blood neutrophils in vitro. J. Nat. Prod. 2003, 66, 994-995. [CrossRef] [PubMed]

31. Scrimgeour, C.M.; Harwood, J.L. Chapter 1: Fatty acid and lipid structure. In The Lipid Handbook, 3rd ed.; Gunstone, F.D., Harwood, J.L., Dijkstra, A.J., Eds.; CRC Press: Boca Raton, FL, USA, 2007; pp. 1-36, ISBN 978-0849396885.

32. Dembitsky, V.M. Betaine ether-linked glycerolipids: Chemistry and biology. Prog. Lipid Res. 1996, 35, 1-51. [CrossRef]

33. Tsantila, N.; Karantonis, H.C.; Perrea, D.N.; Theocharis, S.E.; Iliopoulos, D.G.; Iatrou, C.; Antonopoulou, S.; Demopoulos, C.A. Atherosclerosis regression study in rabbits upon olive pomace polar lipid extract administration. Nutr. Metab. Cardiovasc. Dis. 2010, 20, 740-747. [CrossRef] [PubMed] 
34. Moussaoui, R.; Labbaci, W.; Hemar, N.; Youyou, A.; Amir, Y. Physico-chemical characteristics of oils extracted from three compartments of the olive fruit (pulp, endocarp and seed) of variety chemlal cultivated in Kabylia (Algeria). J. Food Agric. Environ. 2008, 6, 52-55. [CrossRef]

35. Nasopoulou, C.; Zabetakis, I. Agricultural and aquacultural potential of olive pomace a review. J. Agric. Sci. 2013, 5, 116-127. [CrossRef]

36. Caputo, A.; Morone, G.; Di Napoli, M.A.; Rufrano, D.; Sabia, E.; Paladino, F.; Sepe, L.; Claps, S. Effect of destoned olive cake on the aromatic profile of cows' milk and dairy products: Comparison of two techniques for the headspace aroma profile analysis. Ital. J. Agron. 2015, 10, 15-20. [CrossRef]

37. Castellani, F.; Vitali, A.; Bernardi, N.; Marone, E.; Palazzo, F.; Grotta, L.; Martino, G. Dietary supplementation with dried olive pomace in dairy cows modifies the composition of fatty acids and the aromatic profile in milk and related cheese. J. Dairy Sci. 2017, 100, 8658-8669. [CrossRef] [PubMed]

38. Cibik, M.; Keles, G. Effect of stoned olive cake on milk yield and composition of dairy cows. Revue Méd. Vét. 2016, 167, 154-158.

39. Terramoccia, S.; Bartocci, S.; Taticchi, A.; Di Giovanni, S.; Pauselli, M.; Mourvaki, E.; Urbani, S.; Servili, M. Use of dried stoned olive pomace in the feeding of lactating buffaloes: Effect on the quantity and quality of the milk produced. Asian-Australas. J. Anim. Sci. 2013, 26, 971-980. [CrossRef] [PubMed]

40. Vargas-Bello-Pérez, E.; Vera, R.R.; Aguilar, C.; Lira, R.; Peña, I.; Fernández, J. Feeding olive cake to ewes improves fatty acid profile of milk and cheese. Anim. Feed Sci. Technol. 2013, 184, 94-99. [CrossRef]

41. Karantonis, H.C.; Tsantila, N.; Stamatakis, G.; Samiotaki, M.; Panayotou, G.; Antonopoulou, S.; Demopoulos, C.A. Bioactive polar lipids in olive oil, pomace and waste byproducts. J. Food Biochem. 2008, 32, 443-459. [CrossRef]

42. Nasopoulou, C.; Smith, T.; Detopoulou, M.; Tsikrika, C.; Papaharisis, L.; Barkas, D.; Zabetakis, I. Structural elucidation of olive pomace fed sea bass (Dicentrarchus labrax) polar lipids with cardioprotective activities. Food Chem. 2014, 145, 1097-1105. [CrossRef] [PubMed]

43. Are Olive Seeds the Next Superfood? Available online: https://www.oliveoiltimes.com/olive-oil-business / olive-seeds-next-superfood /54716?utm_source=Olive\%20Oil\%20Times\&utm_campaign=077cc80f59\% C2\%ADRSS_E\%E2\%80\%A6 (accessed on 7 January 2018).

44. Lodén, M. Role of topical emollients and moisturizers in the treatment of dry skin barrier disorders. Am. J. Clin. Dermatol. 2003, 4, 771-788. [CrossRef] [PubMed]

45. Van Hoogevest, P.; Wendel, A. The use of natural and synthetic phospholipids as pharmaceutical excipients. Eur. J. Lipid Sci. Technol. 2014, 116, 1088-1107. [CrossRef] [PubMed] 